\title{
O PAPEL DA MULHER NO MEIO PENTECOSTAL: NOVÍSSIMAS RELAÇÕES DE GÊNERO NAS ASSEMBLEIAS DE DEUS
}

Otávio Barduzzi Rodrigues da Costa

otavio.costa@metodista.br

Universidade Metodista de São

Paulo (UMESP), São Bernardo do

Campo, São Paulo, Brasil.

\author{
RESUMO
}

A intenção deste artigo é mostrar as mudanças de gênero ocorridas no cenário Pentecostal Tradicional Brasileiro. Houve a preocupação em escrever acerca disso uma vez que os clássicos acerca do tema não mais alcançam as constantes mudanças pelas quais esse grupo religioso passou nos últimos cinco anos. Para ser mais especifico há de se mostrar aqui as mudanças diversas relacionadas aos costumes, teologia, ética e rituais que as Assembleias de Deus e algumas igrejas que se espelham nelas estão passando sobretudo em relação ao gênero que tradicionalmente se pauta por uma relação machista. A metodologia utilizada é a observação participante decorrente anos de pesquisa entre as Assembleias de Deus. Conclui-se que estão ocorrendo varias mudanças no que se refere as relações de gênero, rituais, teologias e costume dentro desse tipo de pertença religiosa. Aqui há de se enfocar as mudanças em relação ao gênero.
\end{abstract}

PALAVRAS-CHAVE: Pentecostalismo. Gênero e religião. Mudanças sociais. 
A verdadeira religião é a vida que levamos, não o credo que professamos.

Louis Nizer

\section{INTRODUÇÃO}

Estamos em época de mudanças sociais, como um dos principais segmentos da sociedade, a religião também passa por mudanças (BERGER, 1971, p. 21), pode-se afirmar que estamos em época de efervescência religiosa (CAMPOS, 2002 p. 97). Sobretudo no Brasil, profundas mudanças econômicas e sociais, bem como a inserção do país, no cenário econômico mundial afetou vários segmentos da sociedade brasileira e consequentemente, sua religiosidade também foi afetada (MUNIZ DE SOUZA; MARTINO, 2004, p. 15).

Tradicionalmente a relação de gênero nessas igrejas em especial na AD's se caracteriza por uma leitura fundamentalista bíblica descrita em I Timóteo 2:11-12 "A mulher aprenda em silêncio, com toda a sujeição. Não permito, porém, que a mulher ensine, nem use de autoridade sobre o marido, mas que esteja em silêncio" e em 10 Coríntios 14:34-35 "As mulheres estejam caladas nas igrejas, porque lhes não é permitido falar". E, se querem aprender alguma coisa, interroguem em casa a seus próprios maridos, porque é indecente que as mulheres falem na igreja", bem como outras passagens semelhantes, porém tais posições tem sidos mudadas que apresentaremos nesse trabalho.

Essa interpretação relega o papel social da mulher a uma visão machista, baseada no discurso que deve ser protegida, impedindo-a de ser líder em várias igrejas da Assembleias de Deus (AD) e igrejas derivadas desta denominação, pentecostal ${ }^{1}$ tradicionais ou ortodoxas. Além de lhes denegar cargos de liderança, os membros da $A D$ em seu discurso e práticas diárias, tratam suas esposas e filhas como submissas e em um papel secundário impedindo de alcançar suas potencialidades. A mentalidade machista muitas vezes vem das próprias mulheres que para se auto justificar ou serem vista nessa comunidade como Santas ou Mulheres de Deus aceitam esse quadro e ensinam suas filhas e novas fiéis da comunidade a se portar segundo essa visão machista. O problema se agrava quando percebemos que se trata da maior igreja protestante da América latina.

Esta visão machista é mais predominante no Brasil; talvez pela formação pentecostal sócio-histórica predominar uma mentalidade de alienação política (ROLIM CARTAXO, 1987, p. 46). As Iglesias pentecostales (inclusive as asembleias de Dios) da América latina já tiveram uma formação diversa e revolucionária, como no Chile, Venezuela e Uruguai, por exemplo, tais igrejas tiveram papel preponderante nas lutas contra os regimes direitistas e nesses países se configuraram menos machistas (HILARIO, 2010) com um papel valorizado da mulher.

\section{EXPLICANDO UM POUCO.}

Usualmente classifica-se o pentecostalismo Brasileiro em três grandes fases (ou ondas). O pentecostalismo no Brasil tem sido classificado utilizando as ideias de Paul Freston, e se têm usado a periodização das três ondas. A primeira onda 
pentecostal registra a fundação e o surgimento da Congregação Cristã do Brasil e das Assembleias de Deus. A chamada segunda onda pentecostal teve origem na década de 1950, dava ênfase na glossolalia, na cura divina e nos milagres.

Na Década de 70, uma terceira onda pentecostal, que é a mais estudada, por que usa grande espaço na mídia e suas ideias diferenciadas, com uma série de modificações da teologia pentecostal, deu início a formas de pentecostalismo conhecido com o nome de pentecostalismo brasileiro ou neopentecostalismo. A Igreja Universal do Reino de Deus (1977), a Igreja Internacional da Graça de Deus (1980), a Igreja Cristo Vive (1986), são expressões afirmadas do pentecostalismo brasileiro (MARIANO, 2005).

Cada uma focaliza seu discurso social e teológico em bases principais que podem até se misturar com as outras. Todas podem pregar, por exemplo, a cura, ou a prosperidade, mas cada uma enfoca algo que são diretrizes básicas da maioria das pregações em seus templos. A primeira onda (pentecostalismo) enfoca o batismo com o Espírito Santo e a glossolalia e a salvação da Alma (LEONARD, 1963 p. 47). A da segunda onda de (Deuteropentecostalismo) enfoca a cura divina e estimula cultos com excessiva demonstração de Glossolalia (MOREIRA, 1996 p.13). A da terceira exalta o exorcismo e mensagem da prosperidade (FERRARI, 2007 p.22).

\section{NÚMEROS E CARACTERÍSTICAS DAS IGREJAS PENTECOSTAIS.}

Várias igrejas surgiram no cenário Brasileiro nos últimos anos. Basta dar um pequeno passeio em qualquer bairro, sobretudo os periféricos, para ver um sem número de denominações religiosas das mais variadas².

Os números demonstrados pelo Censo de 2010, divulgado recentemente pelo Instituto Brasileiro de Geografia e Estatística (IBGE) apontou que o número de evangélicos cresceu $\mathbf{6 1 , 4 5 \%}$ no Brasil nos últimos dez anos. Apenas entre as Assembleias de Deus o crescimento foi estrondoso, mais de $48 \%$. Se utilizando de Dados do Censo 2010 (que calcula cerca de 13.000.000 - treze milhões de membros até 2009) 3 .

Em que pese à popularidade alcançada, ou a grande colocação na mídia, não é nem de longe o maior representante do pentecostalismo no Brasil, perto das Assembleias de Deus (AD). Segundos dados do IBGE, as maiores representações somadas do neopentecostalismo não se aproximam das ADs que na menor das contagens chega a quinze milhões de membros. Segundo o IBGE a IURD tem 1.873.000 (um milhão oitocentos e setenta três mil membros). A IIGD não aparece nas pesquisas do IBGE, mas segundo uma entrevista dada a revista Enfoque Gospel, com seu fundador o missionário R.R. Soares, que auto atribui-se a cerca de 900.000 (novecentos mil) membros, não há porque duvidar, sendo que em apenas uma pregação no estado do RJ na Enseada de Botafogo, no chamado Dia da Decisão, em comemoração às quatro décadas de jornada ministerial de seu líder, cerca de 200 mil pessoas compareceram (REVISTA ENFOQUE GOSPEL, 2012). A IMPD tem 315.000 (trezentos e quinze mil membros) (IBGE, 2010), outras somadas chegam a 400.000 tais como o Ministério Mudança de Vida, 
Renascer em Cristo, da Comunidade Evangélica Sara Nossa Terra, e do Ministério Internacional da Restauração. Todas essas juntas (cerca de 4,5 milhões de membros) não chegam a um terço das Assembleias de Deus (ADs).

\section{MUDANÇAS DIVERSAS PRESENTES E VINDOURAS. DIFERENÇAS DE COSTUME.}

As ADs tradicionalmente são conhecidas por impor uma adequação moral aos seus membros no que se refere as vestimentas, impõe um jugo pesado inadequado ao clima brasileiro, tachando o que é ou não uma roupa decente. No seu livro o pastor Ricardo Gondim (2005, prefacio) ${ }^{4}$ denúncia o pesado jugo a qual estão dispostos tais pessoas. Essa é uma visão fundamentalista, mas que tem mudado, porém há muito ainda que mudar.

Para a maioria das ADs não se pode cortar cabelo para as mulheres, homens não podem ter cabelo comprido, de preferência o corte deve ser padronizado como o do pastor ou raspado, mulheres só podem usar saia comprida, no mínimo abaixo do joelho, homens podem andar de calça social e camisa, preferencialmente comprida, mas os obreiros no culto só podem portar terno e gravata, não importa o calor (ROLIM CARTAXO, 1987, p. 18).

As assembleias de Deus depois de meados da década de 1940, tem se dividido em ministérios, que seguem mais ou menos a mesma matriz, aceitam os costumes umas das outras, convidam pregadores umas das outras para pregarem, mas estão divididas em ministérios. Isso significa que surge outra igreja sobre outra liderança com controle das receitas da igreja. São inúmeros os ministérios, os mais numerosos são: Ministério Belém, Ministério Ipiranga, Assembleia de Deus Missionária, Assembleia de Deus Ministério Missão, filiadas a CGADB. Há inúmeras outras não filiadas tais como, AD Kairos, AD Restauração, AD Fama, etc... vale a pena registrar a Assembleia de Deus Madureira, que só perde para números de fiéis para a $A D$ Belém, e tem sua própria convenção: $A$ CONAMAD - A Convenção Nacional das Assembleias de Deus no Brasil do Ministério de Madureira.

Porém todas podem ser caracterizadas por certos códigos de comportamento que as caracteriza além da roupa: repetem em tom monocórdio versículos bíblicos, ao menos em tese não falam gírias e palavrões, evitam ouvir músicas mundanas e frequentar eventos mundanos. Não pode (ou não podia já que tem mudado tal visão) várias coisas, ver tevê, praticar esporte e cultuar ritmos musicais brasileiros, as crianças não podiam brincar de futebol, bicicleta ou nadar, nem praticar esportes ou ir à praia. A justificativa é ao mesmo tempo Simples e definitiva: são coisas do mundo ou do diabo ${ }^{5}$. Essa é uma visão fundamentalista bíblica que impunha certa interpretação de lideranças mas que mudou nos últimos anos.

Porém há mudanças, no segundo maior ministério ${ }^{6}$ das ADs. A Assembleias de Deus ministério Madureira tem mudado radicalmente seu costume. A veiculação anunciado por jornais gospel de todo o país confirma a facilmente verificável $^{7}$ a mudança as quais passam. Agora ficou muito mais visível e isso acaba ou acabara interferindo em outras assembleias de Deus, sob o risco de perder fiéis: 
No templo do Brás, porém, às $19 \mathrm{~h} 30$ do domingo 15 , um grupo de cerca de vinte fiéis fazia coreografias, ao lado do púlpito, ao som de uma batida funkeada. Seus componentes - mulheres maquiadas e com cabelos curtos tingidos, calça jeans justa e joias combinando com o salto alto; homens usando camiseta e exibindo corte de cabelo black power - outrora sofreriam sanções, como uma expulsão, por conta de tais "ousadias". Mas ali eram ovacionados por uma plateia formada por gente vestida de forma parecida, bem informal. Palmas, também proibidas nas celebrações tradicionais, eram requisitadas pelo pastor Samuel de Castro Ferreira, líder do templo e um dos responsáveis por essa mudança de mentalidade (...)Sua Assembleia do "pode" tem agradado aos fiéis. "Meu pai não permitia que eu pintasse as unhas, raspasse os pelos ou cortasse o cabelo", conta a dona de casa Jussara da Silva, 49 anos. "Furei as orelhas só depois dos 40 anos. Faz pouco tempo, também, que faço luzes", afirma Raquel Monteiro Pedro, 47 anos, gerente administrativa. Devidamente maquiadas, as duas desfilavam seus cabelos curtos e tingidos adornados por joias pelo salão do Brás, cuja arquitetura, mais parecida com a de um anfiteatro, também se distingue das igrejas mais conservadoras. (CARDOSO, 2011, s/p ).

Tais mudanças se encontram em franca aceitação pelos fiéis e afetam outras Assembleias de Deus e igrejas, que cada vez mais rompem com tradições, a $A D$ do Bom Retiro com mais de 7.000 membros que pode ser citada como exemplo (SANTOS CORREA, 2008, ), mas a maioria das ADs ainda mantém seus costumes.

Especialmente frente à juventude das igrejas já há uma franca mudança de comportamento, tais como uso de camisetas (na maioria sempre se referindo a algo bíblico), uso de calça jeans e corte de cabelo (as mulheres ainda mantêm comprido, mas não mais até a cintura). Parte disso se deve também ao crescimento de grifes evangélicas que produzem roupas de cunho cristão, mas com corte moderno, atendendo a uma fatia do mercado antes inexplorada e agora em franca expansão (CUNHA, 2007). Ainda na maioria das igrejas pentecostais tradicionais ou ortodoxas é obrigatório tanto fora como dentro da igreja o uso de roupas decentes, só que o que é decente tem sido mudado ${ }^{8}$, a 40 a CGADB (Convenção Geral das Assembleias de Deus no Brasil), realizada em abril de 2012 em Cuiabá retificou o que é ou não decente (GCABD, 2012), como por exemplo, a convenção anterior era proibido que mulher usasse pintura e enfeites, a partir dessa convenção, em seu art. $3^{9}$ afirma para se evitar o Uso exagerado de pintura e maquiagem, permitindo o uso, porém com moderação.As ADs e igrejas derivadas a que denominar-se-á igrejas pentecostais ortodoxas, como visto, não estão isentas de mudanças diversas, sobretudo nos últimos anos (de 2007 em diante). Vários eventos proporcionaram tais mudanças. A "explosão Gospel" (CUNHA, 2007 p.9) ocorrida na década de 1990. A influência sempre histórica das igrejas norte-americanas, cujo discurso e teologia foram mudados após os acontecimentos de setembro de 2001. Outro em 2004 quando ocorre à saída da AD Madureira da CGADB. Também a ordenação de mulheres a partir de 2005. Outro com a crescente influência de Algumas ADs na mídia. Digno de nota é a mudança de discurso e sua grande influência teológica dos eventos promovidos pelos Gideões Missionários da Ultima Hora. Também vale lembrar a crescente influência teológica da CPAD e da CGADB, ou seja, há novas instituições influenciando as Igrejas pentecostais ortodoxas. 
Essas mudanças tem forte impacto no modo como tem sido tratada as mulheres, impões - se, sem revolta, mas vagarosa e decididamente uma nova maneira de se portar e de se vestir impactando sua identidade interna e externa. A imagem de senso comum, o crente de terno e gravata pleno calor do Rio de Janeiro com bíblia debaixo do braço, ou a Irmã de saias e cabelos compridos, a senhora, pobre e iletrada cujas agruras sociais são de sofrimento mas, permissão de Deus, ainda existe, porém isso tem mudado. Primeiramente tal identidade significava existir fora do mundo moderno, sem vaidade, sem participar do capitalismo, sem televisão, sem participar de esportes em um semi-isolamento psico-espiritual. Essa identidade tem relação com uma memória histórica que se encontra em plena extinção. Mas é essa identidade esse tipo ideal que me refiro nesse artigo o que as vezes vai se chamar de pentecostalismo ortodoxo ou tradicional.

\section{MUDANÇAS EM RELAÇÃO AO GÊNERO}

As mulheres dentro do ministério tinham um papel secundário em uma visão machista. Em vários ministérios ainda não é aceito que mulheres sejam pastoras. Dentre os que não aceitam estão, por exemplo, o ministério Ipiranga, Belém, Missionária, entre os que aceitam estão os ministérios Madureira, Torre Forte e várias congregações locais. Em 2005 foi consagrada a primeira pastora da denominação centenária, e indo contra a maioria do posicionamento da instituição $^{10}$ : o pastoreado feminino. Embora nunca ordenadas, às mulheres e solteiros já tiveram nos anos 30 e 40 um papel importante nas ADs, porém o que ocorreu de $1940^{11}$ (CARVALHO, 2013) até 1990 foi um conservadorismo extremado (ALENCAR, 2010 p. 76) que implicou em uma fase de machismo em vagaroso declínio da década de 2000 para os dias de hoje.

A ordenação de mulheres, após anos de papel de submissão (MARIZ, 1994) e de incapacidade de ordenação (TOLEDO FRANCISCO, 2002), isso agora mudou; já é aceita a ordenação em várias congregações desde que no dia 23 de abril de 2005, quando foi sagrada pastora, a cantora gospel Cassiane, fato que entrou para a história da Assembleia de Deus. Foi consagrada a primeira pastora da denominação centenária, quebrando um jejum de anos desde Linda Nyström, esposa de Samuel Nyström (ARAUJO, 2007. verbete mulheres) em 1919 na Amazônia e indo contra a maioria do posicionamento da instituição: o pastoreado feminino. Vale registrar que já existem como ordenadas pastoras, a Elizete Malafaia, esposa de Silas Malafaia é um conhecido exemplo, dentre outras ordenações cada vez mais crescentes. Porém não é unânime em todos os ministérios, o que questiona a força das CGADB que reconheceu tais ordenações, mas ainda não se posicionou nem contra nem a favor da ordenação feminina (GOSPEL PRIME - 2011), porém certas mudanças em questão de gênero são claramente perceptíveis.

Embora nunca ordenadas, às mulheres e solteiros já tiveram nos anos $30 \mathrm{e}$ 40 um papel importante nas ADs, o que ocorreu de 1940 até 1990 foi um conservadorismo extremado (ALENCAR, 2010) que implica em machismo (da década de 2000 para cá) em franco declínio. Ultimamente tem se observado uma força maior da CGADB (Convenção Geral das Assembleias de Deus do Brasil) no que se refere às questões teológicas e diminuindo sua força em questões de doutrina $^{12}$. Isso se deve ao fato de multiplicar as denominações associadas sendo 
impossível unificar por enquanto a doutrina de cada igreja. Creio que se deve também a certo medo de sair da convenção como aconteceu com a $A D$ Madureira. Em seu site oficial, ela é definida como "uma igreja evangélica pentecostal que prima pela ortodoxia doutrinária."

A Convenção das Assembleia de Deus do Distrito Federal (CEADDIF -2011), cujo presidente é o Pr. Sóstenes Apolos reconheceu e sagra pastoras. $\mathrm{Na}$ Assembleia Geral Ordinária de setembro - Outubro de 2011, a CEADDIF aprovou o ingresso de mulheres como membros da convenção e a ordenação ao pastorado. A proposta foi aprovada pela maioria dos presentes. A CEADDIF é filiada a CGADB - Convenção Geral das Assembleia de Deus no Brasil, que não tem em seus quadros mulheres como membros, ou pelo menos não tinha até o momento. A CGADB não consagra ministros, quem o faz são as igrejas e o obreiro é reconhecido por seu pastor presidente, que apresentam listas para as Convenções regionais (como a CEADDIF), e após a ordenação, são encaminhadas fichas dos pastores (e das pastoras), para o devido registro junto a CGADB (IDEM).

O que ocorre de fato é que o posicionamento oficial da CGADB é contra o pastoreado feminino, porém suas afiliadas, as convenções regionais, já sagram pastoras e a CGADB fica então obrigada a reconhecer, pois está no seu estatuto o reconhecimento de sacerdotes (não diz o sexo) consagrado pelas convenções regionais (CGADB, estatuto artigo 17). Caso notório, e com evidentes interesses políticos, foi a sagração da Ex senadora Marina Silva consagrada pela convenção do DF em abril de 2012 e na reunião da CGADB em maio já era apresentada como pastora no evento (GOSPEL MAIS - 2012). Até agora a CEADIFF, a CEADMT (do Mato Grosso) e a CEADSP são as que demonstraram um posicionamento oficial de ordenação feminina.

Ainda há certo machismo, sempre tradicional nas ADs (MARIZ, 1994 p. 12), esse machismo é inclusive aceito pela maioria das mulheres, que se põe em papel de submissão visto que há o entendimento geral, entre os homens e a maioria das mulheres de que a Bíblia diz assim (CAMPOS MACHADO, 1996 p. 199). Esse machismo se manifesta de várias maneiras, desde a aceitação geral de que não poderia haver mulheres pastoras, como a ideia de que mulher não trabalha, e que quem sustenta a casa é o homem (IDEM). Porém essa visão têm mudado, há tempos vários pastores, em que pese o machismo na pratica de suas vidas pessoais diárias, dizem em seus discursos e pregações que é grande o papel das mulheres no movimento pentecostal, esse entendimento é compactuado em anos de observação ${ }^{13}$ e também na Bíblia de Estudo Pentecostal (1995) nos comentários de provérbios 31.10-31, como no Dicionário de movimento Pentecostal (ARAUJO, 2007, verbete mulheres). Não há já algum tempo a separação de homens e mulheres nas igrejas da ADs, ainda continuam praticá-la a Congregação Cristã do Brasil e a IPDA, nessas denominações homens sentam do lado direito ao altar e mulheres do lados esquerdo.

Sempre reconhecem a importância da mulher, mas as relegam ao serviço social e de oração da igreja, porém algo pouco relatado é o preconceito que as mulheres tem delas mesmas, é observado que mulheres que trabalham fora, "não estão na visão", e que o "certo seria não trabalhar". Porém com a emancipação recente da mulher e a crescente conquista dos seus direitos esse preconceito tem diminuído, ainda mais porque houve a percepção de que família 
em que a mulher trabalhava aumentava a arrecadação do dizimo. Os cultos ultimamente têm dado grande importância para as mulheres e são homenageadas e chamadas para vários outros trabalhos na igreja ${ }^{14}$. Pode ser ou não por interesse, mas a mulher tem sido mais valorizada.

Quanto à moral sobre o casamento ainda é soberano o fato de se manter a família, quase que a qualquer custo ${ }^{15}$, sabe-se que o pentecostalismo tem uma visão machista (MARIZ, 1994 p. 192), e o divórcio não era aceito pelas ADs. Antes era impensável uma mulher divorciada ser membro, hoje se aceita bem, desde que ela já fosse separada antes da conversão. Está diminuído também o preconceito com mulheres separadas antes da sua conversão ${ }^{16}$, estas no entanto, são estimuladas a perdoar e continuar com seus maridos. O divórcio antes impensável hoje é possível apenas na possibilidade de adultério, e mesmo assim a pessoa deve ser "tratada espiritualmente" antes de se relacionar de novo com alguém $^{17}$. Em 2015 a CONAMAD liberou o divórcio após tratamento pastoral, desde que o pastor declarasse não haver possibilidade entre o casal. A CGADB ainda tem certa resistência ao divórcio.

É um avanço se considerar que antes era impossível. Ainda é um assunto tabu e desafio para a igreja (STRECK, 2007), porém o poder da mulher dentro da igreja tem aumentado ainda que a passos mais lentos que suas conquistas fora dela. Aumentando o seu empoderamento, aumenta-se proporcionalmente a diminuição de preconceito ao divórcio também (FONSECA; MARIN; NASCIMENTO DE FARIAS, 2010, p. 28).

Os pentecostais tradicionais demonizavam a televisão até ocorrer dois fatores: a influência e o sucesso dos televangelistas nos anos 1970. Há de se considerar o crescente acesso econômico para a televisão, ficava fácil demonizar algo que não tinha acesso, desde 1990 ficou permitido à televisão para ver desde que se evitasse programas de nudez ou indecentes, estimulando apenas aos programas religiosos e telejornais (ALENCAR, 2010).

Evidentemente o maior acesso a mídia, a televisão introduziu novas ideias antes impensáveis as irmãs, tal como acesso a moda, ideários de beleza, que embora manipuláveis por uma indústria cultural de interesses escusos deu novas escolhas as pertencentes às assembleias de Deus em sua autoimagem (MIRA, 2003), além do mais o acesso ao computador e a internet, trouxe tremenda possibilidade de comunicação informacional ao mundo pentecostal (CAMPOS JR, 2012) , no que se refere a opressão tradicionalmente machista da Ad's trouxe uma liberdade de trocas de ideias e conversas para as crentes femininas antes impossível e restrita ao seu círculo de amizade.

Trouxe diversas ideias antes totalmente alienadas. Além do padrão de beleza, trouxe também a ideia de introdução no mercado de trabalho e ideários de independência financeira trazidas pelo capitalismo.

\section{TEOLOGIA DA PROSPERIDADE X TEOLOGIA DA SALVAÇÃO.}

A prosperidade para Assembleia de Deus é uma visão bem diferente das neopentecostais. Essas seguem a teologia ou evangelho da prosperidade que teve suas origens nos EUA, por volta dos anos 30 e 40 (MARIANO, 1999). No Brasil, segundo Mariano (1999), a Teologia da Prosperidade iniciou a sua 
trajetória nos anos 70, penetrando em muitas igrejas e ministérios. Cada uma delas deu de diferentes maneiras e de diferentes modos as doutrinas desse evangelho da prosperidade que se baseava em escritos de Hagin tais como: "Não ore mais por dinheiro [...] Exija tudo o que precisar." (HAGIN, p. 17 apud ROMEIRO, 1998, p. 43, grifos nossos). A Teologia da Prosperidade encontrou terreno fértil no Brasil a partir os anos 70, encontrando espaço nos grupos evangélicos pentecostais. Após certo tempo os pentecostais tradicionais começaram a rejeitá-lo (PIERATT, 1993) o que ocasionou, para quem acreditava uma ampla difusão de novas igrejas e divisões que acreditavam nesse tipo de evangelho. Surgiram daí as chamadas igrejas neopentecostais.

A prosperidade para os Assembleianos não significa fartura de bens materiais como é pregada pelas igrejas neopentecostais, e sim paz harmonia e segurança, em várias pregações é constante a definição que prosperidade é viver bem com aquilo que Deus permite que você viva. Ou seja, é um ato continuo de gratidão a Deus pelo que você tem não uma luta para conquistar coisas que o fiel ainda não tem.

Na bíblia de estudo pentecostal (CPAD - 1995), no estudo "Riqueza e Pobreza" observa-se a seguinte afirmação: o crente não deve se preocupar com acúmulos materiais nem amontoar bens...para o cristão as verdadeiras riquezas são o amor e fé.... O que ocorre é que certos germes da teologia da prosperidade tem entrado entre os pentecostais tradicionais fazendo com que muitos creiam nisso, o que pode explicar o crescimento tanto da ADs, que estão aceitando tais mensagens mas não com ponto central da sua teologia que ainda é a salvação das almas. Simplesmente as igrejas pentecostais ortodoxas estão sofrendo influência de outras pentecostais, tais como as neopentecostais proporcionando diversas e inúmeras mudanças.

Aos poucos a teologia da prosperidade tem chegado aos pentecostais ortodoxos, se por um lado aliena e escraviza os seus fiéis, por outro possibilita uma coisa no que se refere ao gênero, induz a mulher a procurar e se inserir no mercado do trabalho. Antes a mulher que era relegada as tarefas do lar era o modelo a ser seguido, porém agora o modelo é a da mulher formada, empresaria e principalmente dizimista na Igreja.

Por causa desta nova forma de pensar a prosperidade agora a mulher independente e empresaria financeiramente, por trazer dízimos e receita tem mudado a mentalidade frente a sua independência financeira. Ora se agora a mulher pode trabalhar e trazer dizimo, se ela não tiver um papel preponderante e de liderança na igreja, se não puder escolher o que vestir ela vai mudar de igreja pois há uma disputa do mercado religioso no Brasil (OLIVEIRA, 2010).

\section{CONSIDERAÇÕES FINAIS}

Como pode se notar as igrejas pentecostais a que se classificam aqui de pentecostais ortodoxas, especialmente as Assembleias de Deus, passam por profundas mudanças em seus direcionamentos morais e teológicos. O mundo está passando por grandes mudanças em todas as áreas. Mudanças há sempre na história, mas a intensidade do momento é única. 
A mídia também muda o modo de como a igreja se relaciona com o seu fiel e vice versa. SANTOS CORREA $(2000$, p. 87) afirma: "A relação que é criada através da mídia social, oferece exatamente a associação que se busca no espaço público", assim o fiel antes negado no espaço público pela discrepância econômica, o encontra na igreja, na mídia social em vários espaços, este começa a aparecer e a gostar disso, o sentimento de humildade cristão vai sumindo, e criando novas relações sociais dentro do grupo religioso que muda cada vez mais as Igrejas.

Note-se que é a mensagem da teologia da prosperidade e da estrutura organizacional da Igreja, a conversão do mercado religioso, os fiéis e como a religião influencia cada vez mais mudanças em uma causalidade circular. É o surgimento de uma comunidade religiosa, que é de consumo de bens, e de um sentido de pertença, onde há uma reunião simbólica de interesses através da mídia em influenciar suas teologias e práticas tradicionais mesmo entre os pentecostais ortodoxos. Aliado a isso, há um medo da perda de fiéis por parte da liderança da Igreja, esses então permitem certas mudanças que devem ser cuidadosamente estudadas, a fim de direcionar o estudo do campo religioso brasileiro atual.

É necessário um novo estudo religioso e a constante observação participante para manter atualizado o estudos dessas religiões que preocupam pela sua cada vez mais crescente influência na política e economia.

Não vamos dizer que já há uma total independência da mulher, aliás independência é um conceito contrário na tradição pentecostal, seja para homem, seja para mulher. Porém já alguns passos têm sido dados e se pode observar um avanço nas relações de gênero nessa pertença religiosa. Claro que ainda existem as Ad's que mantém o seu tradicionalismo machista (ex as AD's ministério Ipiranga que ainda mantém homens e mulheres em lados opostos da igreja), mas isto deve mudar com a crescente mudança e inserção da mulher nas suas conquistas de direitos.

É certo que com acesso aos meios de educação de qualidade o povo brasileiro, assim como os Assembleianos podem a vir mudar radicalmente de ideia sobre as conquistas de direitos de gênero que quiçá possam ser influenciados por alguns pastores militantes. Porém assim como esses assuntos dividem opiniões dentro da sociedade Brasileira, assim também o é entre o meio Assembleiano. A opinião nunca é unanime, e entre jovens Assembleianos, com mais acesso a estudo as opiniões já se encontram radicalmente contra o discurso apresentado entre os mais conservadores. O futuro é visto com esperança de melhora. 


\title{
THE ROLE OF WOMAN AMONG PENTECOSTAL DEVICE: NEW RELATIONS OF GENDER IN THE ASSEMBLIES OF GOD
}

\begin{abstract}
The intent of this article is show all the changes in the scenario of Brazilian Pentecostal orthodox Churches. There was concern in writing about it since the classics on the subject no longer reach the constant changes that this religious group spent the past five years. In particular the Assemblies of God, the object of this study. To be more specific here is to show the various changes related to customs, theology, ethics and rituals that the Assemblies of God and some churches that mirror them are going through. The methodology used is participant observation due more than seven years of research among the Assemblies of God. We conclude that several changes are occurring regarding gender relations, rituals, theologies and custom within this type of religious affiliation. Here we will indicate the changes about gender relationship.
\end{abstract}

KEYWORDS: Pentecostalism. Gender and religion. Social change. 
1 Existe o que Alencar (2013) chama de assembleianismo difuso, igrejas pentecostais que não são da $A D$ mas que se espelham em seus modos, pois derivavam delas. $O$ termo denominação é uma divisão de igreja, se uma igreja nova, torna-se denominação. Na analise dos grupos religiosos, Berguer (1971) analisando Weber aponta os conceitos são de seita e Igreja. A denominação, por sua vez, pode ser definida como uma etapa intermédia entre seita e Igreja (Freston, 1994). A denominação pertence a uma corrente não institucionalizada como um modo de ser, assim como o pentecostalismo, há inúmeras igrejas pentecostais, como as $A D s$ que são dividas em denominações, assim existe a $A D$ Madureira, A AD Belém e outras, assim como do pentecostalismo e das AD nasce outras igrejas como a igreja pentecostal guerreiros da fé, igreja pentecostal do deus vivo, essas também são denominações.

2 Existem muitas listas sobretudo WEB segue sugestões de consulta: http://www.compulsivo.com.br/2010/02/todas-as-igrejas-do-brasil.html http://www.pulpitocristao.com/2010/05/confira-os-nomes-de-igrejas-maisestranhos-e-engracados/

http://oskaras.com/97-nomes-estranhos-de-igrejas/ http://www.gospel10.com/igrejas/denominacao--batista--1 http://www.gospel10.com/igrejas/denominacao--igreja-pentecostal--18 http://www.mackenzie.br/10175.html

3 O órgão oficial de Notícias das Assembleias de Deus (doravante AD), o CPADNews, que professa o número (feito por pesquisa própria através de registros das igrejas) anunciado da Convenção Geral das Assembleias de Deus o Brasil (CGADB) de não vai se entrar no mérito de confiabilidade dessa pesquisa (CPADNews, 2012) o mesmo site observa que se a taxa de crescimento continuar constante, em 2020 o número de evangélicos da AD ultrapassará os 50.000.000.

4 Criado e pastor da Assembleia de Deus por 15 anos, o pastor Ricardo Gondim com 50 anos de idade e vivencia dentro dessa igreja, observou muitas coisas nelas e depois abriu sua própria igreja (Igreja Evangélica Betesda) por não acreditar em certas regras e costumes impostos pela ADs.

5 Para alguns fiéis é a mesma coisa pois interpretam ao pé da letra a passagem bíblica descrita em 1Jo 5.19 "Sabemos que somos de Deus e que o mundo inteiro jaz no Maligno."

6 Ver mais detalhes na reportagem - Um pastor moderno entre os radicais jornal mídia gospel de 20 de novembro de 2011, disponível em http://www.midiagospel.com.br/variedades/noticias/assembleia-de-deus-semusos-e-costumes acessado em 12/dez/2012.

7 Basta ir a qualquer culto.

8 Se baseiam na Bíblia em 1 epistola a Timóteo 2.9.

9 a integra dessas regras estão disponíveis em

http://www.confrateres.com.br/informes 120711.html

10 Apesar de haver ordenação ainda há muita resistência, a resistência está centrada nas igrejas que ainda não tem pastoras ou não convidaram pastoras 
para pregar, após isso ocorrer a resistência pouco a pouco se dissolve (GOSPEL PRIME - 2011).

11 A incapacidade de ordenação de mulheres foi decidida na reunião da CGADB de 1941, após certo Acumulo de poder que foi visto pelos homens como problema, em que a missionária Frida Vingren não aceitara o poder masculino.

12 Logo será objeto de artigo próprio.

13 O autor é presbítero de uma das Assembleias de Deus há mais de 7 anos.

14 Por exemplo, a esposa do autor consagrada a diaconisa, como é publicitária e designer é constantemente procurada para fazer a arte dos cartazes de campanhas e outros serviços.

15 Mesmo em caso de traição e agressão familiar há o estimulo para que o membro vitima perdoe o outro e haja reconciliação de casal, o ministério de casal tem sido um dos mais poderosos das igrejas.

16 Ha pouco preconceito com homem separado ou divorciado, tanto é que há vários pastores consagrados que são separados, porém todos passam por "tratamento espiritual" nesse caso, que pode ser alguns anos ou meses sem pregar, estando no Banco sendo orientado por um pastor e tendo um grupo de intercessores orando por ele(a).

17 As convenções omitem muita coisa, a CGADB apenas diz que é para manter a família, mas se omite em caso de divórcio.

\section{REFERÊNCIAS}

ALENCAR, Gedeon Freire. Protestantismo tupiniquim: hipóteses da (não) contribuição evangélica à cultura brasileira. São Paulo: Arte Editorial, 2005

ALENCAR, Gedeon Freire. de. Pentecostalismo Hitech: uma janela aberta, algumas portas fechadas.História Agora, São Paulo, v. 1 (Religiões e Religiosidades), p. 428-453, fev. 2010.

ARAUJO, Isael. Dicionário do movimento pentecostal. Rio de Janeiro: CPAD, 2007

BERGER, Peter . La Religion dans la Conscience Moderne. Essai d'analyse culturelle, Paris. Centurion Paris, Ed. Sociales. 1971.

BÍBLIA português. Bíblia de Estudo Pentecostal.Trad. João Ferreira de Almeida. Edição rev. e corrigida. Rio de Janeiro - RJ :CPAD-1995

BORELLI, Viviane. Mídia e religião: entre o mundo da fé e o do fiel. Rio de Janeiro, 
CAMPOS JR, Luis de Castro . Pentecostalismo: sentido da palavra divina. São Paulo, SP:Editora Ática. 1995.

CAMPOS, Leonildo Silveira (2002). As mutações do campo religioso. In: Caminhando, vol. 7, n. 1 [9], 2002, p. 97-109 [Edição on-line, 2009] disponível em: http://www.sumarios.org/sites/default/files/pdfs/34368 4381.PDF acesso em 06/dez/2012

CAMPOS, Leonildo Silveira.(2005). As origens norte-americanas do pentecostalismo brasileiro: observações sobre uma relação ainda pouco avaliada. REVISTA USP, São Paulo, n.67, p. 100-115, setembro/novembro

CAMPOS MACHADO, Maria das Dores. Carismáticos e pentecostais, Adesão Religiosa na Esfera Familiar, Revista Brasileira de Ciências Sociais (RBCS) da ANPOCS, Rev. bras. Ci. Soc. v. 09. n. 36 São Paulo. Fev. 1996

CARVALHO, O. L. 2013. Memória coletiva e pentecostalismo - Frida Vingren, a pioneira esquecida. Ciências da Religião (Mackenzie.), v. 11, p. 59-70, 2013.

CARDOSO, Rodrigo. Um Pastor moderno entre os radicais, Isto é, São Paulo -SP25/05/2011, no 2167, disponível em http://istoe.com.br/138157 UM+PASTOR+MODERNO+ENTRE+OS+RADICAIS/, acesso em 22/03/2015

CGADB, Convenção geral das Assembleias de Deus no Brasil (2012) resoluções CGADB - 40a reunião da CGADB - Resoluções - disponível em http://cgadb.org.br/home5a/fotos1/, acesso em 13/dez/2012.

CONTINS, Marcia; GOMES, Edlaine de Campos. Autencidades e edificações religiosas: comparando carismáticos católicos e neopentecostais. Revista Anthropológicas. Recife, UFP, 2008.

CONDE, Emílio. História das Assembleias de Deus no Brasil, Rio de Janeiro- RJ: CPAD. 2011;

CPAD -lições bíblicas - estudo sobre a verdadeira prosperidade. Out-dez 2011 Comentários bíblicos de pastor Leonardo Bibiano. Autoria de lições CPAD.

CPADNews . Jornal das casas publicadoras das Assembleias de Deus - números da AD. Brasil não será mais católico. 2012. disponível em: http://www.cpadnews.com.br/integra.php? $\quad s=25 \& \mathrm{i}=13601-$ acesso em 06/dez/2012, 
CUNHA, Magali do Nascimento. A explosão Gospel, um olhar das ciências humanas sobre o cenário evangélico no Brasil, RJ-RJ, Mauad editora. 2007.

EETAD. Homilética. Falando de Deus aos homens. CPAD, Campinas -SP, 2000a.

FERRARI, Odêmio Antonio. A Igreja Universal do Reino de Deus e o exercício do poder. São Paulo, SP: Ave-Maria. 2007.

FONSECA, André Dioney; MARIN, Jérri Roberto; NASCIMENTO DE FARIAS, Marcilene. Relações de gênero e cultura religiosa: um estudo comparado sobre a atuação feminina na igreja evangélica luterana do Brasil e Assembleia de Deus. Revista de História Comparada, .Rio de Janeiro, 4-1: 6-41, 2010.

FRESTON, Paul, Breve história do pentecostalismo brasileiro. In: ANTONIAZZI, Alberto et al, Nem anjos, nem demônios: interpretações sociológicas do pentecostalismo, Petrópolis, Vozes, 1994.

GONDIM, Ricardo. É proibido-O que a Bíblia permite e a igreja proíbe. Editora Mundo Cristão - São Paulo-SP.2005.

GOSPELPRIME - jornal de noticias evangélicas (2011), AD no distrito federal ordena mulheres como pastoras - publicado em 04/2011 disponível em :http://noticias.gospelprime.com.br/assembleia-de-deus-distrito-federalpastoras-mulheres/, acesso em 10/dez/2012.

HAGIN, Kenneth E. O Toque de Midas, t. Original The Midas Touch - Traduzido por Natan Rufino, São Paulo-SP, RHEMA Brasil Publicações. 1988.

HILARIO, W. 2010 "Un ensayo sobre sociología del pentecostalismo en clave política a partir de Christian Lalive dÉpinay y El Refugio, Revista Cultura y Religión, UNAP, pp. 3-39.

IBGE-2010 , Dados estatísticos sobre religião no Brasil, ftp://ftp.ibge.gov.br/Censos/Censo Demografico 2010/Caracteristicas Gerais R eligiao Deficiencia/tab1 4.pdf,

LEONARD, Emilie G . Protestantismo Brasileiro, São Paulo, Aste. 1963.

MATOS, Aldari Souza de. 0 movimento pentecostal: reflexões a propósito do seu primeiro centenário. Fides Reformata, São Paulo, Ano 11, n. 2, p. 23-50, 2006. 
MARIANO, Ricardo. Neopentecostais: sociologia do novo pentecostalismo no Brasil. São Paulo, SP: Loyola. 1999.

MARIANO, Ricardo. Expansão pentecostal no Brasil: o caso da Igreja Universal. Estudos Avançados de religião. vol.18, n.52, 2004, pp. 121-138.

MARIZ, Cecília. Alcoolismo, Gênero e Pentecostalismo. Religião \& Sociedade, Rio de Janeiro, v. 16, n.03, p. 80-93, 1994.

MIRA, Maria Celeste. O masculino e o feminino nas narrativas da cultura de massas ou o deslocamento do olhar. Cadernos Pagu (21), Campinas-SP, p. 13-38. 2003.

MOREIRA, A. Novas igrejas e movimentos religiosos: 0 pentecostalismo autônomo. Cadernos do IFAN, 15, 7-58. 1996.

MUNIZ DE SOUZA, Beatriz; MARTINO, Luís Mauro Sá. Sociologia da religião e mudança social-Católicos, protestantes e novos movimentos religiosos no Brasil, São Paulo - SP: Paulus. 2004

OLIVEIRA, Amurabi Pereira de. Disputas e estratégias de legitimação no campo religioso: uma interpretação a partir da teoria de Bourdieu dos novos movimentos religiosos brasileiros. Revista espaço acadêmico, n¹09. Jun. 2010. P. 148-154

PIERATT, Alan. O evangelho da prosperidade: análise e resposta. São Paulo: Edições Vida Nova, 1993.

PRANDI, Carlo; GIOVANNI Filoramo. - As ciências das religiões, São Paulo: Paulus 1999.

REVISTA ENFOQUE GOSPEL, (2011) R. R. Soares e seu ministério, revista independente de noticiais do evangelho, Rio de Janeiro, Ed. Edição 82 - MAI / 2011, disponível em: http://www.revistaenfoque.com.br/index.php?edicao=82 \&materia=1067 acesso em 05/dez/2012.

ROLIM CARTAXO, Francisco. O Que É Pentecostalismo, Editora Brasilense, São Paulo, 1987.

ROMEIRO, Paulo. Super Crentes. O Evangelho segundo Kenneth Hagin, Valnice 
SANTOS CORREA, Marina Aparecida Oliveira dos. Análise dos ministérios da igreja assembleia de Deus e a sua lógica de funcionamento, Tese de doutorado em ciências da Religião, PUC-SP, orientador, Dr. João Décio Passos. 2008.

SANCHIS, Pierre. Religiões, Religião... Alguns Problemas do Sincretismo no Campo Religioso Brasileiro, in Pierre Sanchis (org.). Fiéis \& Cidadãos - Percursos de Sincretismo no Brasil. Rio de Janeiro, Eduerj. 2001

STRECK, Valburga Schmiedt (2007) Famílias em transição:desafios para a sociedade e Igreja, Estudos Teológicos, v. 47, n. 1, p. 25-42, 2007

TOLEDO FRANCISCO, Crislaine Valeria de. Passagens híbridas: relações de gênero e pentecostalismo. Faculdade de Filosofia, Letras e Ciências Humanas da USPtese de mestrado em sociologia, Defesa em 2002-08-16 São Paulo,2002, Orientador: Negrao, Lisias Nogueira.

Recebido: 31 de março de 2014.

Aprovado: 10 de junho de 2016.

Como citar:

COSTA, O. B. R.. O papel da mulher no meio pentecostal: novíssimas relações de gênero nas assembleias de Deus. Cad. Gên. Tecnol., Curitiba, v. 9, n. 33, p. 60-76, jan./jun. 2016.

Correspondência:

Otávio Barduzzi Rodrigues da Costa

Av. Bispo Cesar Dacorso Filho, 691, Rudge Ramos, São Bernardo do Campo - SP, CEP, 69031-000.

Direito autoral: Este artigo está licenciado sob os termos da Licença Creative Commons Atribuição 4.0 Internacional.

\section{(c) (i)}

